\title{
The Host-Parasite Relationship between Freshwater Crayfish and the Crayfish Disease Fungus Aphanomyces astaci: Responses to Infection by a Susceptible and a Resistant Species
}

\author{
By T. UNESTAM* AND D. W. WEISS $\uparrow$ \\ Department of Bacteriology and Immunology and Cancer Research Genetics \\ Laboratory, University of California, Berkeley, California 94720, U.S.A.
}

(Accepted for publication 7 October 1969)

SUMMARY

In studies of the responses to infection by the crayfish disease fungus $A p h a$ nomyces astaci of the susceptible European crayfish Astacus astacus and the resistant Western American species Pacifastacus leniusculus, the latter was consistently more resistant to infection by injection or via aquarium water; the difference in resistance was more striking in the second method. The American crayfish was only slightly less sensitive than the European crayfish to the toxic action of large numbers of dead spores of $A$. astaci and to infection by living spores of another phycomycete, Entomophthora apiculata, which is not a natural parasite of crayfish. A. astacus acquired a significantly higher degree of resistance to infection by injection or via the ambient water as a result of two previous exposures to sublethal numbers of spores of the pathogenic fungus.

The two strains of Aphanomyces astaci tested behaved identically within the cuticular layer of the exoskeleton of both crayfish species, showing strain-dependent degrees of ability to penetrate and grow within the cuticle. The epicuticle offered a major barrier to penetration in both hosts. The fungus was unable to establish growth within the musculature and developed only sparsely along the ventral nerve cord of living animals of both species; fungal growth was luxurious shortly before and after the death of both crayfish. Aggregation of injected spores and their encirclement by haemocytes occurred rapidly in living Astacus astacus as well as in Pacifastacus leniusculus, but melanization of the spore aggregates and hyphal elements was considerably more pronounced in the resistant crayfish, $P$. leniusculus. The observations suggest the participation of at least some active processes of native and acquired resistance of crayfish to the crayfish disease fungus, particularly in the internal tissues and the epicuticle.

Evidence has been found for the existence of specifically acquired means of defence against microbial disease in invertebrates, but there is little information as to whether such animals can respond with reactions to foreign macromolecules akin to the immunological response of vertebrates (Smith, Miescher \& Good, 1966; Pathology Society Symposium, 1967; Seaman \& Robert, I968). Recognition mechanisms which

* Present address: Institute of Physiological Botany of the University of Uppsala, Uppsala, Sweden.

$\dagger$ Present address: Department of Immunology, Hebrew University-Hadassah Medical School, Jerusalem, Israel. 
permit an organism to distinguish between closely related substrates in the process of phagocytosis, including the discrimination between self and non-self substances, have been shown in invertebrates (Boyden, 1963). The relationship between capacity to discriminate in phagocytosis and acquisition of heightened resistance to microbial pathogens, and the relative importance of acquired defence reactions in ability to withstand invasion and disease from the numerous potentially parasitic microorganisms in the environment, also remain largely unknown. Most of the attempts to discover in invertebrates mechanisms similar to the antibody response of all animals phylogenetically above the primitive fish have been in the direction of searching for immunoglobulin-like factors against antigens bearing no relation to the natural environment of the animal. It is not impossible, however, to conceive that invertebrate species can mount antibody-like reactions to alien substances, but in a more restricted range, and perhaps only or largely against foreign chemical determinants of agents which pose threats to survival. It would be surprising if as complex a family of molecules as the vertebrate immunoglobulins had arisen de novo at the level of the hagfish or lamprey eel; and related though less evolved molecules, still capable of some of the biological activities of antibodies, would not be an unexpected component of the host responses of the more highly developed invertebrates.

To explore further the occurrence, nature and biological significance of specific recognition mechanisms in the response of invertebrates to foreign molecules, a systematic study was undertaken of the host-parasite relationship between two closely related species of freshwater crayfish and an aquatic phycomycete. The European crayfish Astacus astacus is highly susceptible to the fungus Aphanomyces astaci Schikora, the causative organism of 'Krebspest' or crayfish plague or disease, whereas the west coast American crayfish Pacifastacus leniusculus Dana is highly resistant.

It is apparent that crayfish are endowed with resistance mechanisms markedly effective against some micro-organisms but not against others. The outer surface of their exoskeleton is exposed to, and frequently occupied by, a variety of microorganisms which are incapable of invading the internal living tissues, not even through small wounds, although they have the enzymic equipment for penetration and are able to do so readily, spreading quickly through the body, after death of the host. On the other hand, crayfish are very susceptible to several varieties of protista. This differential refractoriness, and the large variation in resistance to a given microorganism, by otherwise very similar species of host, suggested the crayfishAphanomyces system as a good model for the study of specificities in the behaviour of invertebrates towards foreign chemical configurations.

The crayfish disease appeared in Italy during the I860s (Seligo, 1895), and swept through large parts of Europe in succeeding decades, eradicating the population of Astacus astacus wherever it erupted. It appears that no members of this species survived in attacked waters; at least, resistant populations have not been reported. Similar plagues have not been described among non-European crayfish species.

Schäperclaus (1935, 1954) and Nybelin (1936) showed that the causative agent of this disease was Aphanomyces astaci, and they described the characteristic disease picture. Fungal hyphae are invariably present in and on limited areas of the exoskeleton of infected crayfish, commonly in the soft areas of joints and abdominal segments where penetration usually occurs; involvement of the cuticle is often limited and difficult to detect. After penetrating the skeleton, the hyphae are frequently seen to 
grow along the ventral nerve cord and brain ganglion, but growth is often restricted largely to the vicinity of the cuticular penetrations; the tissues around these foci sometimes become yellow or brown and necrotize. Hyphae are occasionally seen in the eye, but seldom in other organs. Late in the disease, hyphae grow outwards from foci of infection on the skeleton, forming zoosporangia and zoospores in the surrounding water. Death of the host occurs within several days to weeks after infection with symptoms of neurotoxicity, the animals failing to respond to external stimuli during the last days of life.

Aphanomyces astaci has not been isolated as a free-living organism, and may be incapable of surviving for long away from a host (Rennerfelt, I936; Unestam, I969). European freshwater crayfish are its only known natural hosts. The fungus does not attack Orconectes limosus Rafinesque (Cambarus affinis), an American freshwater crayfish which was introduced to Europe and now inhabits water formerly occupied by Astacus astacus (Schäperclaus, I954), or any other American species tested, but it does cause a frequently fatal infection of a Japanese species and of the crab Eriocheir sinensis Milne Edwards (Benisch, 1940) under laboratory conditions. No special growth requirements by the fungal mycelium have been found (Unestam, I965). The present communication reports the findings of experiments to determine quantitatively the differential degree of susceptibility to this fungus by crayfish of the two species, to ascertain whether survivors of a sublethal infection acquire a heightened resistance to a second challenge, and to delimit the major areas of interaction between host and parasite.

\section{METHODS}

Crayfish. Specimens of Pacifastacus leniusculus were obtained by trapping from Lake Tahoe, in the Sierra Nevada mountains between California and Nevada, and from Alpine Lake, in Marin Country, north of San Francisco. Astacus astacus came from Lake Ullvättern in Värmland, Sweden. Sample specimens of both species are shown in Pl. I, fig. I.

The animals were maintained in aquaria at $5^{\circ}$ for storage. During experimentation, they were kept in groups of $\mathrm{I} 5$ or fewer in aquaria containing 71 . pond water, at I $6.5 \pm 0 \cdot 3^{\circ}$. In experiments where fungal spores were added to the aquarium water, doubly glass-distilled water was used in place of pond water. The aquaria were under continuous aeration. The crayfish were fed once weekly with carrot slices, which were removed after I day if not eaten; however, when spores were added to the water, no food was given to the animals for several weeks. In most experiments, intermolt crayfish of 70 to $90 \mathrm{~mm}$. body length were used; smaller animals were occasionally used in duplicate trials. In any one experiment, care was taken to use animals of only very similar size.

Fungi. The origin of the strains of Aphanomyces astaci here studied, J I and D I, and the culture methods and techniques for obtaining spores have been described previously (Unestam, 1965, 1966 b). Zoospores obtained by exposure of mycelial suspensions to a mixture of pond and distilled water overnight were separated from the hyphal elements by filtration through cheesecloth. The spore suspensions were concentrated by low-speed centrifugation, and the concentrations of spore suspensions in homologous sera or water were determined by haemocytometer counts. The viability of spores was tested by spreading samples of suspension over peptone glucose agar; 
degree of germination was ascertained by direct microscopic examination after incubation for $20 \mathrm{hr}$ at $23^{\circ}$ in a $10 \%(\mathrm{v} / \mathrm{v}) \mathrm{CO}_{2}$ in air atmosphere. All $A$. astaci spore suspensions showed a germination frequency of 10 to $20 \%$.

Some other fungi were also tested: Aphanomyces laevis de Bary, a saprophyte obtained from the Centraalbureau voor Schimmelcultures, Baarn, Holland; an Aphanomyces species shown by Fowles (1967) to act as a wound parasite of freshwater dolphin, kindly made available by Dr B. Fowles (Department of Biology, Colby College, Waterville, Maine, U.S.A.; Entomophthora apiculata Thaxter, an insect parasite, kindly sent us by Dr S. R. Dutky (Entomology Research Division, U.S.D.A. Agricultural Research Service, Beltsville, Md.). The different Aphanomyces species were grown in the same manner as the $A$. astaci cultures; their spore preparations consistently exhibited germination frequencies of 50 to $90 \%$. The Entomophthora was grown on agar containing 0.0I3 $\mathrm{M}$-phosphate buffer ( $\mathrm{pH} 5.5$ ), I \% Difco BactoPeptone, $5 \%$ glucose and $0 . \mathrm{I} \% \mathrm{MgSO}_{4} 7 \mathrm{H}_{2} \mathrm{O}$; the conidiospores were collected from the lids of the culture dishes, and showed germination frequencies of the order of $30 \%$.

Infection experiments. For infection by injection spores were suspended in pooled sera of the corresponding host species, obtained by permitting the bloods to coagulate and removing the clots by light centrifugation. Samples $(0.05 \mathrm{ml}$.) of the serum + spore suspensions were injected ventrally into the subabdominal haemocoel, between the third and fourth abdominal segments, left of the nerve cord and very close to it, Serum was used to suspend the spores in order to decrease physiological disturbance to the animals; injections of saline have been considered to be harmful (Crowley, 1964). In other experiments, infection was via the environment, by adding known numbers of spores to the aquarium water.

The animals were usually observed for 2 months after infection, but death occurred in most instances within the first 3 weeks. Death was ascribed to the infection only when living hyphae were found in the tissues or exoskeleton on post-mortem examination. When infection was via the aquarium water, the entire skeleton was examined for the presence of fungal growth if there was no gross involvement of the abdominal cuticle or the central nervous tissue. LD 50 values were calculated by the method of Reed \& Muench (1938).

The brown or yellow-brown pigment designated as 'melanin' was readily soluble in $\mathrm{N}-\mathrm{NaOH}$ at $60^{\circ}$, but not in cold $\mathrm{NaOH}$ or in $95 \% \mathrm{H}_{2} \mathrm{SO}_{4}$, Io $\mathrm{M}-\mathrm{HCl}$, acetone, xylene, chloroform or dimethyl ether.

\section{RESULTS}

Differential susceptibility of Astacus astacus and Pacifastacus leniusculus to living and killed spores of Aphanomyces astaci and other phycomycetes

The production of toxins by Entomophthora species and other fungal pathogens of arthropods has been described by several investigators (MacLeod \& Loughheed, 1965; Prasertphon, 1967; Yendol, Miller \& Behnke, 1968), and it seemed possible, therefore, that Aphanomyces astaci toxins could also play a role in the crayfishfungus interaction. Preliminary experiments indicated that zoospores of this fungus could induce rapidly manifested toxic effects in crayfish when injected in large quantities, in addition to initiating progressive infection. Experiments were therefore con- 
ducted in both species of crayfish with spores killed by acetone or by freezing and thawing (exposure to $-20^{\circ}$ for $30 \mathrm{~min}$.), to determine whether there existed a differential degree of susceptibility to toxic action by the parasite. The results of a typical experiment with freeze-killed spores of $A$. astaci strain $\mathrm{J}$ I are presented in Table I. It appears from Table I that freeze-killed spores had a similar degree of toxicity for Astacus astacus and Pacifastacus leniusculus, with the former showing slightly greater susceptibility, both in terms of the number of spores constituting one LD 50 dose and of length of survival after infection. Identical findings were obtained in repeated experiments.

Table I. Susceptibility of crayfish Astacus astacus and Pacifastacus leniusculus to injection of spores of Aphanomyces astaci strain $\mathcal{F} \mathrm{I}$, killed by freezing and thawing*

\begin{tabular}{|c|c|c|c|c|}
\hline \multirow{2}{*}{$\begin{array}{l}\text { Number of spores } \\
\text { of } A . \text { astaci injected }\end{array}$} & \multicolumn{2}{|c|}{ Animals dead/total } & \multicolumn{2}{|c|}{ Mean time to death (days) } \\
\hline & P. leniusculus & A. astacus & P. leniusculus & A. astacus \\
\hline $6 \times 10^{6}$ & $8 / 9$ & $10 / 10$ & $x \cdot 8$ & $I \cdot O$ \\
\hline $2 \times 10^{6}$ & $4 / 9$ & $7 / 9$ & 5.5 & $3 \cdot 3$ \\
\hline $6 \times 10^{5}$ & $0 / 9$ & I $/ 9$ & - & $I .0$ \\
\hline LD50 & $2.5 \times 10^{6}$ & $I \times 10^{6}$ & - & - \\
\hline
\end{tabular}

Table 2. Susceptibility of crayfish Astacus astacus and Pacifastacus leniusculus to injection of living spores of Aphanomyces astaci strain $\mathcal{F I}^{*}$

$\begin{array}{ccccc}\begin{array}{c}\text { Number of spores } \\ \text { of } A \text {. astaci injected }\end{array} & P . \overbrace{\text { leniusculus }}^{\text {Animals dead/total }} & \text { A. astacus } & \overbrace{P . \text { leniusculus }}^{\text {Mean time to death (days) }} & \text { A. astacus } \\ 6 \times 10^{5} & 8 / 8 & - & 4 \cdot 2 & - \\ 2 \times 10^{5} & 2 / 9 & 8 / 8 & 5 \cdot 0 & 9 \cdot 9 \\ 6 \times 10^{4} & 0 / 9 & 8 / 9 & - & 9 \cdot 4 \\ 2 \times 10^{4} & - & 4 / 8 & - & 13.5 \\ 6 \times 10^{3} & - & 1 / 5 & - & 15 \cdot 0 \\ \text { LD50 } & 3 \times 10^{5} & 2 \times 10^{4} & -\end{array}$

Spore-free filtrates of suspensions of acetone-killed zoospores of Aphanomyces astaci proved not to be toxic, suggesting that the toxic properties of the spores were bound firmly within, or on, the spore structure.

Similar experiments were now initiated with living spores of Aphanomyces astaci, using numbers of zoospores below the gross toxic threshold. Most of the crayfish given such numbers of spores remained seemingly unaffected for several days. All the animals which died thereafter showed some degree, and sometimes even a considerable amount, of fungal spread and growth; deaths commonly occurred within the first I5 days after challenge. The results of a representative experiment with strain J I are shown in Table 2. As seen from Table 2, the European crayfish was significantly more susceptible to challenge with living spores of the crayfish disease fungus. This finding was obtained in repeated similar experiments with this strain, the difference in susceptibility between the two host species ranging from to to 20 times the number of living spores constituting one LD 50 dose. An identical experiment was made with living spores of strain D I of the Aphanomyces pathogen; the LD 50 dose for Astacus astacus was $5 \times 10^{4}$ spores and for Pacifastacus leniusculus $2 \times 10^{6}$ spores. 
To test the specificity of the different resistances of the two species of crayfish to the pathogenic fungus, groups of the animals were now challenged with living spores of the insect parasite Entomophthora apiculata (not a natural parasite of crayfish, though injection of large numbers of conidiospores can cause intoxication or progressive infection leading to death). The observations recorded in this experiment are seen in Table 3. At the highest spore concentration, $\mathrm{I} \cdot 5 \times 10^{5}$, Entomophthora rapidly killed all the animals of both species of host; penetration of the exoskeleton from within and some hyphal development were none the less seen in many of the crayfish at death. With smaller numbers of spores, there was a suggestion of somewhat greater susceptibility by $A$. astacus, the dying animals all showing typical symptoms of infection, but the difference between the European and American crustaceans in relation to the naturally parasitic $A$. astaci was not clear here. Injection of $10^{6}$ living spores of two other phycomyces species not naturally pathogenic to crayfish, the Aphanomyces dolphin wound organism and Aphanomyces laevis, resulted neither in death nor in any evidence of hyphal growth or penetration of the cuticle, despite the fact that these fungi are also active chitinase producers (Unestam, 1966a).

Table 3. Susceptibility of crayfish Astacus astacus and Pacifastacus leniusculus to injection of living spores of a fungus parasitic of insects Entomophthora apiculata*

Number of spores of E. apiculata injected

$$
\begin{gathered}
1.5 \times 10^{5} \\
3 \times 10^{4} \\
6 \times 10^{3} \\
\text { LD } 50
\end{gathered}
$$

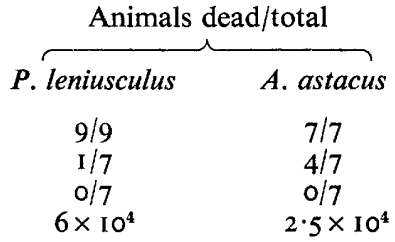

* Spores injected in homologous serum.
Mean time to death (days)

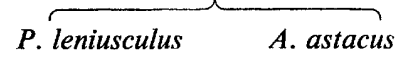

$\cdot 9 \cdot 6$

$24 \cdot 2$

Table 4. Susceptibility of crayfish Astacus astacus and Pacifastacus leniusculus to infection with living spores of Aphanomyces astaci strain D I in aquarium water

Number of spores/ml. aquarium water

$2.5 \times 10^{4}$
$2.5 \times 10^{3}$
$2.5 \times 10^{2}$
$2.5 \times 10^{1}$
LD $50 \dagger$

$2.5 \times 10^{4}$

$2.5 \times 10^{2}$

LD $50+$
Animals dead/total

$\begin{array}{cc}P . \overbrace{\text { leniusculus }} & \text { A. astacus } \\ 2 / 4 & - \\ 0 / 4 & 7 / 7 \\ 0 / 5 & 7 / 7 \\ 2.5 \times 10^{4} & 3 / 7^{*} \\ & 3 \times 10^{1}\end{array}$

Mean time to death (days)

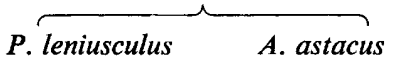

$8 \cdot 5$

- 6

- 8.I

14.0

* All of the remaining four crayfish died, but relatively late after challenge: one on day 28 and three on day 36 ; these animals showed slight symptoms of fungal infection. They may have succumbed to secondary infection by an unrelated micro-organism, or to late infection with Aphanomyces spores.

$\dagger$ LD50 values expressed in terms of number of spores $/ \mathrm{ml}$. aquarium water.

An experiment was now made to assay the susceptibility of the crayfish Astacus astacus and Pacifastacus leniusculus to infection by Aphanomyces astaci via the natural route, i.e. by introduction of spores into aquarium water. As evident from Table 4, only a few spores $/ \mathrm{ml}$. water were necessary to induce lethal infection of A. astacus, whereas the LD 50 dose for the American crayfish remained high, $2.5 \times 10^{4}$ spores $/ \mathrm{ml}$. 
The difference in susceptibility of the two crayfish species was thus even greater when infection was by the natural route than when it was established by injection into the haemocoel.

\section{Acquisition of specifically heightened resistance by Astacus astacus}

Attempts were made to determine whether prior contact with sublethal numbers of living spores of Aphanomyces astaci could induce heightened resistance in Astacus astacus towards subsequent lethal infection. A single exposure to $3 \times 10^{3}$ living spores, by injection, failed to provide conspicuous immunity against challenge with $4 \times 10^{4}$ spores 2.5 weeks later. In contrast, two prior injections of $3 \times 10^{3}$ living spores each, 2.5 weeks apart, bestowed a significant degree of heightened resistance against challenge 2.5 weeks later with $4 \times \mathrm{IO}^{4}$ spores (Table 5). Six of the surviving crayfish (A. astacus) of the immunized group were then placed in an aquarium with a living spore content of $800 / \mathrm{ml}$. water (strain D I), I 7 days after challenge with $4 \times 10^{4}$ spores. A group of nine control crayfish was placed into the same aquarium; all of these control animals developed progressive infection and died, with a mean survival time of 10.9 days; in contrast, only three of the six previously exposed crayfish succumbed to the superinfection from outside, with a mean survival time of $18 \cdot 3$ days.

Table 5. Acquisition of heightened resistance by crayfish Astacus astacus against injection with living spores of Aphanomyces astaci as result of previous sublethal exposure

\begin{tabular}{|c|c|c|c|c|c|}
\hline \multirow[b]{2}{*}{ Animals } & \multicolumn{3}{|c|}{ Number of spores* injected, on days } & \multirow{2}{*}{$\begin{array}{l}\text { Animals } \\
\text { dead/total }\end{array}$} & \multirow{2}{*}{$\begin{array}{l}\text { Mean time to death } \\
\text { (days after last } \\
\text { infection) }\end{array}$} \\
\hline & I & 19 & 37 & & \\
\hline $\begin{array}{l}\text { Immunized } \\
\text { Control }\end{array}$ & $\begin{array}{c}3 \times 10^{3} \\
0(\text { serum })\end{array}$ & $\begin{array}{c}3 \times 10^{3} \\
0(\text { serum })\end{array}$ & $\begin{array}{l}4 \times 10^{4} \\
4 \times 10^{4}\end{array}$ & $\begin{array}{l}1 / 15 \\
7 / 14\end{array}$ & $\begin{array}{l}(7) \\
10 \cdot 6\end{array}$ \\
\hline
\end{tabular}

* Spores of Aphanomyces astaci strain JI, were used; the spores were suspended inhomologous serum. All animals dying showed considerable fungal involvement.

Table 6. Acquisition of increased resistance by crayfish Astacus astacus against infection with living spores of Aphanomyces astaci strain $¥ \mathrm{I}$ as result of previous sublethal exposure; repeat experiment

\begin{tabular}{|c|c|c|c|c|c|}
\hline Animals & \multicolumn{3}{|c|}{ Number of spores injected* } & $\begin{array}{c}\text { Animals dead/ } \\
\text { total }\end{array}$ & $\begin{array}{l}\text { Mean time to death (days } \\
\text { after last infection) }\end{array}$ \\
\hline Immunized & $10^{4}$ & $10^{4}$ & $5 \times 10^{4}$ & $2 / 8$ & IO \\
\hline Control & 0 & 0 & $5 \times 10^{4}$ & $8 / 9$ & I I \\
\hline
\end{tabular}

A repeat experiment on the acquisition of heightened resistance by $A$. astacus yielded similar results (Table 6). Studies are now in progress to determine the specificities of origin and direction of this acquired resistance of $A$. astacus to the crayfish disease fungus. The results here reported indicate at least that these invertebrates can acquire a considerable degree of heightened resistance against a naturally parasitic micro-organism under circumstances very similar to those which pertain to specific immunization of higher animals. 


\section{Spore germination and mycelial growth of Aphanomyces astaci in crayfish blood in vitro}

Experiments were made to determine whether the blood of normal crayfish of the two species possessed different capacities for supporting mycelial growth and spore germination of the plague fungus. The spore germination incidence of both strains of Aphanomyces astaci was observed after incubation for $20 \mathrm{hr}$ in pooled blood of both crayfish species, and the weight of the mycelial growths at 48 and $68 \mathrm{hr}$ was determined. Both fungus strains behaved similarly in the blood of Astacus astacus and Pacifastacus leniusculus, thus indicating that the differential susceptibility of the two species of crayfish did not lie with any differential humoral ability to support growth and germination of the pathogen.

\section{Behaviour of Aphanomyces astaci within the tissues of Astacus astacus and Pacifastacus leniusculus}

Infection by injection. The events in $A$. astacus and $P$. leniusculus following injection of Aphanomyces astaci zoospores appeared to be qualitatively and quantitatively very similar: shortly after introduction into the haemocoel, the spores were seen to be aggregated in clumps on the surface of the ventral nerve cord, encapsulated by large numbers of blood cells (P1. I, fig. $2 a, b$ ). Such clumping of spores was rarely seen elsewhere. Melanization of the clumps was evident within several hours. Hyphae grew out of the masses only when these were composed of large numbers of spores; the escaping hyphae were rapidly surrounded by more blood cells, thereby increasing the size of the original aggregates. The accumulation of blood cells around growing hyphae was often so dense that the fungal structures became difficult to see (Pl. I fig. 3 ). In vitro studies showed no clear evidence of chemotactic attraction of the blood cells to spores or hyphae; their localization around the fungus may have been the result, at least initially, of random collision. On the other hand, the melanization reaction around the spores and hyphae aggregated on the nerve cord was considerably more rapid and intense with $P$. leniusculus than with $A$. astacus (Pl. 2, fig. $4 a, b, c)$. The melanin deposits were also more pronounced and distinct around living than around killed spores. It seemed that deposits of melanin offered mechanical barriers to the spread of the fungal mycelium; thus, heavy melanization around a hyphal tip was frequently seen to result in a breaking through of hyphal branches subapically, where the melanin deposits were usually lighter (Pl. 3, fig. 5). In both host crayfish, the processes of melanization, blood cell aggregation, and clumping of fungal structures on the nerve cord were on the whole very similar vis-à-vis the other Aphanomyces species as well, and towards Entomophthora apiculata.

When spores of Aphanomyces astaci were injected directly into the musculature of either Astacus astacus or Pacifastacus leniusculus, germination and some hyphal development were often seen at first. The outgrowing hyphae were rapidly and heavily melanized, however, and progressive mycelial development was never seen within the muscles.

The active nature of the retardation or inhibition of spore germination and mycelial growth was evident throughout this study; fungal growth and spread usually became marked shortly before or after death of the host. Even Entomophthora apiculata, 
which rarely initiated extensive mycelial growth as long as the crayfish were alive, was able to do so from the spore aggregates on the nerve cord within hours after the animals died (Pl. 3, fig. 6). It was obviously difficult to measure the observations on the behaviour of the crayfish disease fungus and other phycomycetes in Astacus astacus and Pacifastacus leniusculus. The only clear and repeatedly evident difference between the susceptible and resistant crayfish in the reaction to the pathogen within the tissue was the more marked melanization response of the American crayfish. The gross appearance of both crayfish in the later stages of the disease was the same as in animals infected via the aquarium water (see below).

Infection via the aquarium water. Hyphal growth was invariably seen in the exoskeleton of Astacus astacus infected from outside, although at low spore concentrations in the water only small areas, sometimes limited to the joint membrane of a single leg or pleopod, showed frank involvement. Mycelial growth along the ventral nerve cord was usually sparse, and could sometimes not be detected at all at post-mortem examination; encapsulation of fungal structures on the cord was limited in most animals. There was no invasion of muscular tissues. The dorsal side of attacked segments often discoloured before death. Paralysis of the entire abdomen was frequently observed I or 2 days before death, and the pathological picture was consistent with the suggestion that neurotoxic effects were the major cause of death in the crayfish (see Nybelin, 1936; Schäperclaus, 1954).

\section{Behaviour of Aphanomyces astaci in the exoskeleton of Astacus astacus and Pacifastacus leniusculus}

Infection by injection. Once germination had begun from numbers of zoospores sufficient to initiate progressive disease, the events in both host species were very similar. In most instances, hyphae growing out from spores of Aphanomyces astaci strain $\mathrm{J}$ I injected into the haemocoel eventually penetrated the exoskeleton from inside and developed within the cuticular layer, but almost always to a limited extent. In both types of crayfish, the penetrating hyphae were surrounded by heavy melanin deposits in the cuticular layer close to the epidermis and in the layer adjacent to the epicuticle, but not in the intermediate cuticle; melanization was even more pronounced with Entomophthora apiculata. With $A$. astaci strain D I, penetration and growth in the cuticle was heavy, in both $A$. astacus and $P$. leniusculus. Although the LD 50 dose of injected spores of $A$. astaci strain D I was higher than that for strain $\mathrm{J}$ I, strain D I was much more virulent when introduced into the ambient water. Further studies are under way to analyse this suggested correlation between virulence of infection by the natural route and ability to grow well within the cuticular structure of the host.

In further experiments, sections of the subabdominal exoskeleton of normal crayfish were disinfected with ethanol, cut out, and set in sterile Petri dishes. Spore suspensions were then placed either on the epicuticular surface or on the inner surface from which muscle and epidermis had been removed. Spores from strains J I and D I germinated and penetrated the cuticle from the inner surface. The first hyphae reached the epicuticle from inside and broke through it after about $40 \mathrm{hr}$, in sections from both host species (Pl. 3, fig. 7). Penetration never occurred from the epicuticular surface with either strain of fungus, unless the epicuticle was first pricked with a needle or peeled although normally shaped hyphae grew along this surface. Similar results were 
obtained with disinfected sections of exoskeleton in continuously aerated distilled water containing $7 \times \mathrm{IO}^{3}$ spores $/ \mathrm{ml}$. Penetration took place only from the endocuticular surface. After several days, the sections of exoskeleton in infected, but not in sporefree, waters became soft and lost resistance to mechanical stress, very possibly because of chitinase attack on the cuticular matrix (Unestam, 1966a). Swelling of the hyphal tip was commonly seen when hyphae reached the epicuticle from inside; this was never the case when hyphae encountered inert mechanical obstacles on an agar surface. No obvious differences were observed in the behaviour of excised exoskeleton sections derived from Astacus astacus and Pacifastacus leniusculus.

Infection via the aquarium water. As described above, the sites of attack even in the susceptible crayfish were usually difficult to find during the first several days after the animals were placed in infected water, even when large numbers of spores $\left(\mathrm{IO}^{4} / \mathrm{ml}\right.$.) of the virulent Aphanomyces astacus D I strain were used. Penetration was most commonly evident in the area of joints and body openings. This was consistent with in vitro experiments which showed the undamaged epicuticular surface to be highly resistant to attack. It thus appears that successful fungal penetration may well be conditional on localized absence of the epicuticular membrane or on accidental damage or strain to it, as in the joint areas where cuticular folding occurs. When penetration did take place, hyphal branching was seen within the cuticle itself in less than two days; melanization was evident around the puncture, near the surface of the epicuticle, but not deeper. In the resistant crayfish, penetration of the exoskeleton was never seen within 23 days in water containing $10^{4}$ spores $/ \mathrm{ml}$. In several instances, hyphae were found growing along the outside surface of the exoskeleton, heavily melanized, perhaps as result of some 'etching' of the epicuticular layer.

The importance of the epicuticular membrane in the crayfish's defence against Aphanomyces astaci became further evident in an experiment in which this layer (and probably some of the immediately adjacent cuticle) was peeled away from one intersegmental abdominal membrane of a number of Pacifastacus leniusculus. Of four such animals placed into water containing a sub-LD 50 number of living spores (A. astaci strain D I), $7 \times 10^{3} / \mathrm{ml}$, three died within ro days with heavy involvement of the naked areas. Neither intact $P$. leniusculus put in such water, nor specimens similarly peeled and placed in non-infected water, were adversely affected. The resistant crayfish could similarly be made susceptible to fatal outside infection in water containing $7 \times 10^{3}$ spores $/ \mathrm{ml}$. of $A$. astaci strain $\mathrm{D}$ I by merely pricking the abdominal intersegmental membranes with a fine needle in several places, with fungal penetration clearly limited to the wounds. In parallel experiments, it was found that a majority of Astacus astacus could be made to succumb to otherwise sublethal numbers of spores of $A$. astaci strain $\mathrm{J} \mathrm{I}$ in the surrounding water by previous peeling of small areas of the intersegmental membranes. Once penetration had occurred in either host species, hyphae again grew outwards through the exoskeleton. In later stages of the disease in heavily infected animals, but especially in $A$. astacus, sections of the exoskeleton became brown and necrotic, and brown pigment stained the underlying muscles despite their freedom from fungal growth. 


\section{DISCUSSION}

It appears that the first and a major defensive barrier of crayfish against the crayfish disease fungus consists of the non-chitinous proteolipid epicuticular membrane and, perhaps, of the most nearly adjacent cuticular stratum which is often also damaged in experiments designed to remove or injure the epicuticle alone. The defensive role of the epicuticular membrane has also been suggested for insects (Koidsumi, 1957; Sussman, 195 I $a, b$ ). In intact animals of the susceptible European crayfish, fungal penetration occurred only in limited regions, largely where the epicuticle was missing, damaged or presumably strained; it was not seen at all in the resistant Western American species even when the infected waters contained as many as $10^{4}$ virulent spores $/ \mathrm{ml}$. Following experimental breaking of this membrane, however, even the resistant crayfish Pacifastacus leniusculus exhibited susceptibility to fatal infection in heavily contaminated water.

It is possible that the epicuticle offers resistance to fungal penetration in part for mechanical reasons, and that trapping of the spores in ducts, folds and areas of injury facilitates invasion at these sites. That at least some active and specific processes also participate in epicuticular resistance is indicated by the melanization reactions prominent in this layer, and by the differential pathogenicity of Aphanomyces astaci strains J I and DI by the exterior route. The differences in host resistance between the crayfish Astacus astacus and Pacifastacus leniusculus, and the state of heightened resistance which could be elicited in the former may also be expressed at least partly at the level of the epicuticle. The observation that penetration and involvement of the cuticle by hyphae growing from within the crayfish following injection of the parasite, and from the inner surface of isolated fragments of exoskeleton in vitro, was very similar in both species is in line with this suggestion. On the other hand, the fact that fungal invasion from outside is much more common at sites of epicuticular absence or injury indicates that the considerably greater native resistance of $P$. leniusculus and the increased acquired resistance of the European crayfish must also depend on mechanisms functioning within deeper layers of the exoskeleton, the internal tissues and the areas of the body openings.

The ability of hyphae of Aphanomyces to transverse the epicuticular membrane in both crayfish species from inside does not argue against the important defensive role of this structure: there may be significant differences in the morphological and physiological characteristics of the membrane presented at its interior and exterior surfaces, and, in addition, the already developing hyphae which reach the membrane from the endocuticular side undoubtedly pose a very different challenge than do isolated spores impinging from without.

Although the interaction between $A$. astaci and crayfish of both species within the cuticle itself appeared to be identical, at least grossly, once progressive infection was under way, it was observed (T. Unestam, to be published) that the blood of the resistant crayfish $P$. leniusculus was more capable of inhibiting the extracellular chitinase activity of the fungus than was the blood of Astacus astacus. Death often occurred in infected crayfish of both species with little fungal growth either within or without the cuticle, perhaps caused by toxic substances liberated by the fungus in the cuticular stratum or produced as a result of host reactions against the invader. The ability to retard fungal enzymic action and/or proliferation could thus be imagined 
to constitute a second line of defence, within the cuticle, should epicuticular penetration occur. The internal tissues of the living crayfish appear to constitute a poor environment for the development of the parasite: large numbers of spores must be injected to initiate progressive infection even in the susceptible crayfish A. astacus; there is very little fungal involvement of most internal tissues; and, where fungal growth does occur (along the ventral nerve cord and ganglion), it is very limited. The involvement of the nerve cord in some of these studies might have been at least partially the consequence of deposit by injection of large numbers of spores in its vicinity, in the abdominal haemocoel. Moreover, rapid clumping of spores and hyphal elements and encirclement by large numbers of blood cells was a ubiquitous event in both species.

The difference in susceptibility to injection of spores between the European and American crayfish was not as great as the difference in susceptibility to extrinsic infection, but it was still marked. The greater internal resistance of Pacifastacus leniusculus was accompanied by a considerably more pronounced melanization of spore and hyphal aggregates on, and in the vicinity of, the nerve cord. The pertinence of this observation to resistance, and whether melanin deposition is, indeed, cause or effect of microbial inhibition, remain unknown. Melanin formation has been suggested by a number of investigators as an arthropod defence mechanism against microbial attack, but its causal role in resistance states awaits confirmation (Briggs, 1964). Recent studies (Kuo \& Alexander, 1967; Metlitskii \& Ozeretskovskaya, I968) have indicated an inhibitory effect by melanin and other phenolic compounds on proteases, chitinases and other extracellular enzymes, and there might thus exist a relationship between the larger melanin response of $P$. leniusculus and the greater chitinase inhibition of its body fluids. Whether it is melanin formation or another mechanism, active defence processes apparently come into play against the crayfish disease fungus on the level of the internal tissues as well, once penetration through the exoskeleton has taken place. The active nature of these defences was also apparent from the luxurious fungal growth supported by these tissues of the crayfish shortly before and after death. The cuticular pore channels which connect the epidermis with the epicuticular region in the crayfish may continue to function in the less heavily mineralized parts of the exoskeleton even after moulting (Dennell, I960; Travis \& Friberg, 1963). It is possible that by virtue of this communication system some of the same humoral or cellular resistance mechanisms which are manifested towards injected spores are also operative at the level of the cuticular and epicuticular strata towards spores introduced from outside and towards mycelial elements.

A significant degree of increased resistance was evoked in Astacus astacus as result of preceding sublethal exposure to living spores of Apharomyces astaci. Experiments are now in progress to determine whether this acquired resistance of the European crayfish, and the natively higher refractoriness of $P$. leniusculus, reside in humoral or in cellular factors or in both, and to isolate these. From these studies it should eventually become apparent whether the natural and acquired resistance phenomena here described are related to classical immunological mechanisms.

This work was supported by an Institutional Research Grant from the American Cancer Society, IN-87A; by a grant from the Swedish Natural Science Research Council; and by funds from the Swedish Water Power Industry. The final draft of this manuscript was prepared while one of us (D. W. Weiss) was a guest of The 
Institute for Cancer Research, 770 I Burholme Avenue, Fox Chase, Philadelphia, Pennsylvania I9III, U.S.A. We acknowledge with appreciation the comments and suggestions of Professor Moshe Shilo in the interpretation and presentation of the data.

\section{REFERENCES}

BENISCH, J. (1940). Künstlich hervorgerufener Aphanomyces-Befall bei Wollhandskrabben. Zeitschrift für Fischerei und deren Hilfswissenschaften 38, $7 \mathrm{I}$.

Boyden, S. (1963). Cellular recognition of foreign matter. International Review of Experimental Pathology 2,3 II.

BrigGs, J. D. (I964). Immunological responses. In The Physiology of Insecta. Ed. by M. Rockstein, vol. 3, p. 259. New York: Academic Press.

Crowley, G. J. (1964). Studies in arthropod serology. II. An invertebrate response to injected antigenic materials. Wasmann Journal of Biology 22, I85.

Dennell, R. (1960). Integument and exoskeleton. In The Physiology of Crustacea. Ed. by T. H. Waterman, vol. I, p. 449. New York: Academic Press.

Fowles, B. (1967). Factors affecting Growth and Reproduction of Aphanomyces. Doctoral Thesis, University of California, Berkeley.

KoIDsUmI, K. (1957). Antifungal action of cuticular lipids in insects. Journal of Insect Physiology I, 40.

KUO, M. J. \& AleXANDER, M. (1967). Inhibition of the lysis of fungi by melanins. Journal of Bacteriology 94,624 .

MacLeod, D. M. \& Loughheed, T. C. (1965). Entomogenous fungi. Recent Progress in Microbiology 8, I4I.

MetlitskiI, L. V. \& Ozeretskovskaya, O. L. (1968). Plant Immunity. New York: Plenum Press.

NyBELIN, O. (1936). Untersuchungen über die Ursache der in Schweden gegenwärtig vorkommenden Krebspest. Meddelanden från Statens Undersöknings-och Försögsanstalt för Sötvattensfisket 9, I.

Pathology Society Symposium. (1967). Defense reactions in invertebrates. Federation Proceedings. Federation of American Societies for Experimental Biology 26, I664.

PRASERTPHON, S. (1967). Mycotoxin production by species of Entomophthora. Journal of Invertebrate Pathology 9, 281.

ReEd, L. J. \& Muench, H. (1938). A simple method of estimating fifty per cent endpoints. American Journal of Hygiene 27, 493.

RenNerfelt, E. (1936). Untersuchungen über die Entwicklung und Biologie des Krebspestpilzes Aphanomyces astaci Schikora. Meddellanden från Statens Undersöknings-och Försögsanstalt för Sötvattensfisket ro, I.

SCHÄPERCLAUS, W. (1935). Die Ursache des pestartigen Krebssterbens. Zeitschrift für Fischeri und deren Hilfswissenschaften 33, 343.

SCHÄPERCLAUS, W. (1954). Fischkrankheiten. Berlin: Akademie Verlag.

SEAMAN, G. R. \& RoBERT, N. L. (I968). Immunological response of male cockroaches to injection of Tetrahymena pyriformis. Science, New York 161, 1359.

Seligo, A. (I 895). Bemerkungen über Krebspest, Wasserpest, Lebensverhältnisse des Krebses, Zeitschrift für Fischerei und deren Hilfswissenschaften 3247.

Smith, R. T., Miescher, P. A. \& Good, R. A. (1966). Phylogeny of Immunity. Gainesville, Florida: University of Florida Press.

Sussman, A. S. (195I $a$ ). Studies of an insect mycosis. I. Etiology of the disease. Mycologia 43, 338.

Sussman, A. S. (195I $b$ ). Studies of an insect mycosis. II. Host and pathogen ranges. Mycologia 43, 423.

Travis, D. F. \& Friberg, U. (I963). The deposition of skeletal structures in the Crustacea. VI. Microradiographic studies of the exoskeleton of the crayfish Orconectes virilis Hagen. Journal of Ultrastructure Research $9,285$.

UnESTAM, T. (1965). Studies on the crayfish plague fungus Aphanomyces astaci. I. Some factors affecting growth in vitro. Physiologia Plantarum $18,483$.

UnesTAM, T. (I966a). Chitinolytic, cellulolytic, and pectinolytic activity in vitro of some parasitic and saprophytic oomycetes. Physiologia Plantarum r9, 15.

UNESTAM, T. (1966 b). Studies on the crayfish plague fungus Aphanomyces astaci. II. Factors affecting zoospores and zoospore production. Physiologia Plantarum 19, II IO. 
UNeSTAM, T. (1969). On the adaptation of Aphanomyces astaci as a parasite. Physiologia Plantarum 22, 221.

Yendol, W. G., Miller, M. E. \& BehnKe, C. N. (1968). Toxic substances from entomophthoraceous fungi. Journal of Invertebrate Pathology 10, 313.

EXPLANATION OF PLATES

\section{Plate I}

Fig. I. The European freshwater crayfish, Astacus astacus (left), and the Western American variety, Pacifastacus leniusculus (natural size).

Fig. $2 a$. Nerve cords of two specimens of $A$. astacus 4 days after injection into the abdominal haemocoel of a sublethal dose of spores of Aphanomyces astaci. The spores are clumped on the surface of the nerve cords and are surrounded by aggregates of blood cells. $\times 7$.

Fig. $2 b$. Encapsulated spores in a clump adhering to the nerve cord of a specimen of $A$. astacus 4 days after sublethal infection with Aphanomyces astaci. Surrounding the spores (dark) can be seen large numbers of haemocytes. $\times 150$.

Fig. 3. Hyphae of Strain J I of Aphanomyces astaci growing out into the haemocoel of a specimen of $A$. astacus from a spore clump on the surface of the ventral nerve cord, 5 days after infection by injection. The hyphae are surrounded and almost obscured by aggregates of haemocytes. X I IO.

Plate 2

Fig. $4 a$. Ventral nerve cords of specimen of $P$. leniusculus (left) and $A$. astacus (right) $45 \mathrm{hr}$ after injection of $5 \times 10^{5}$ spores of Strain $\mathrm{J}$ of Aphanomyces astaci into the abdominal haemocoel. Melanization in the attached blood cell-spore aggregates is considerably more pronounced in Pacifastacus. (Nerve cords fixed in alcohol and mounted in Canada balsam to minimize light scattering in the nerve tissue and to emphasize the melanin.) $\times 2$.

Fig. $4 b, 4 c$. Spores melanized within two of the clumps shown in Fig. $4 a$. P. leniusculus specimen on the left, A. astacus on the right. $\times 250$.

\section{Plate 3}

Fig. 5. Melanized hyphal tip of Aphanomyces astaci, Strain $\mathrm{J}$, in clotted blood within abdominal cavity of a specimen of $P$. leniusculus. A hyphal branch is seen developing subapically. $\times$ I I 00.

Fig. 6. Outgrowth of hyphae of Entomophthora apiculata from a spore-haemocyte clump on ventral nerve cord of $P$. leniusculus, $3 \mathrm{hr}$ after death of the host. $\times 95$.

Fig. 7. Outer, epicuticular surface of a section of intersegmental membrane of a specimen of $P$. leniusculus, showing fungal hyphae penetrating to the surface from the cuticular layer within. The membrane fragment was infected in vitro, on the inner surface of the cuticle, with spores of Strain D I of Aphanomyces astaci, $40 \mathrm{hr}$ previously. Swelling of the hyphal tips was a typical phenomenon when hyphae reached the epicuticle of either crayfish species from within, in vitro as well as in vivo. $\times 260$. 

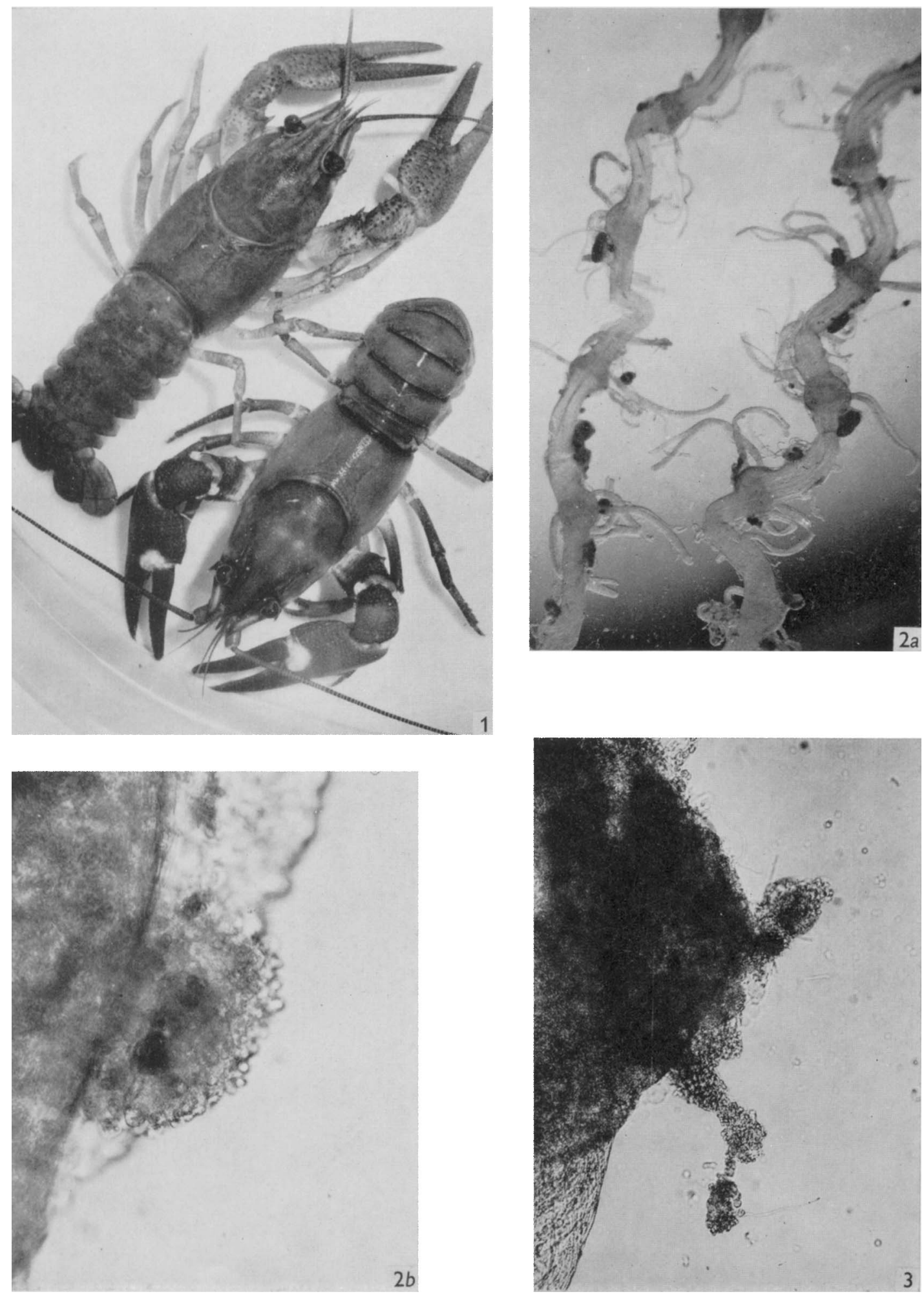

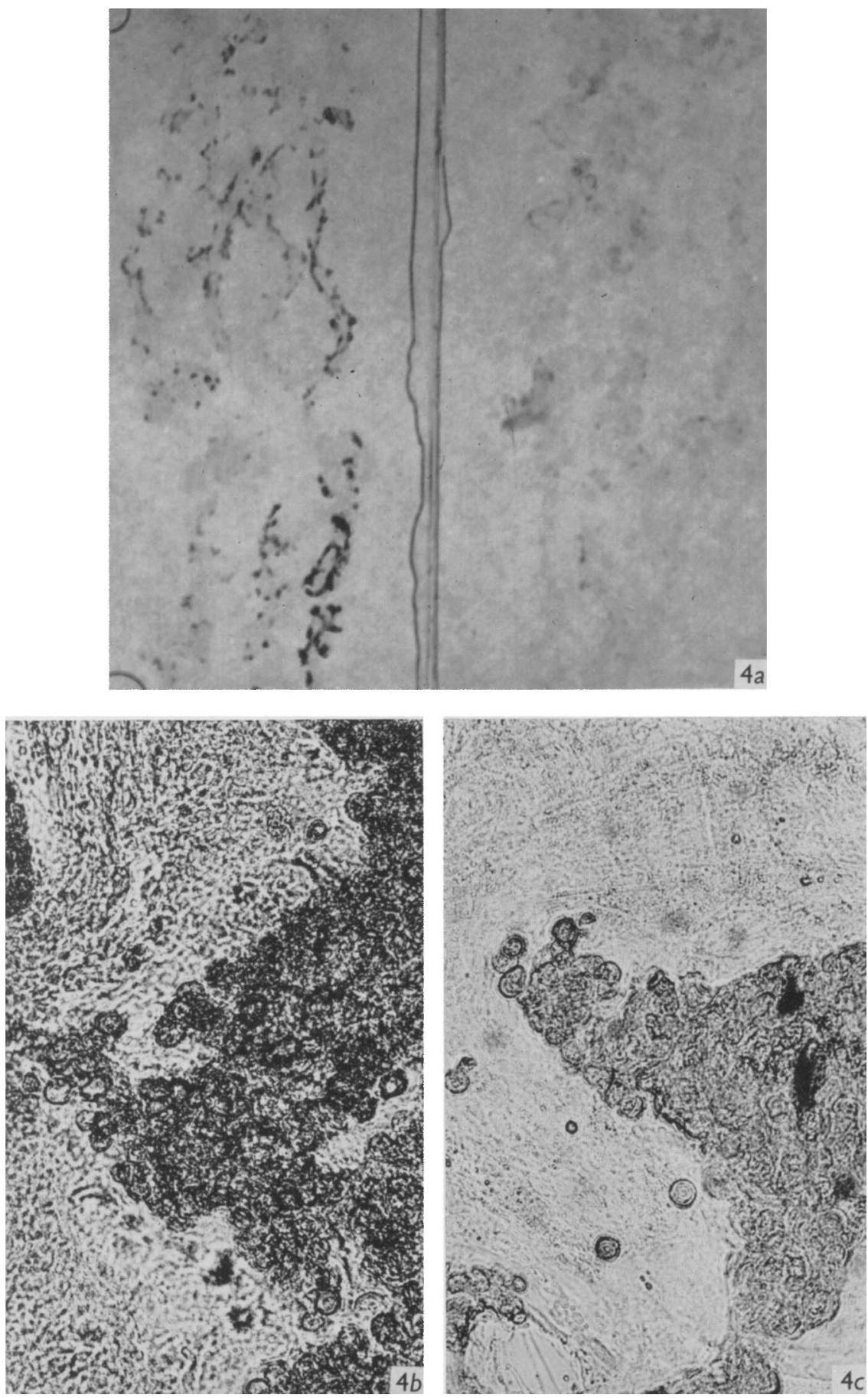

T. LNESTAM AND D. W. WEISS 

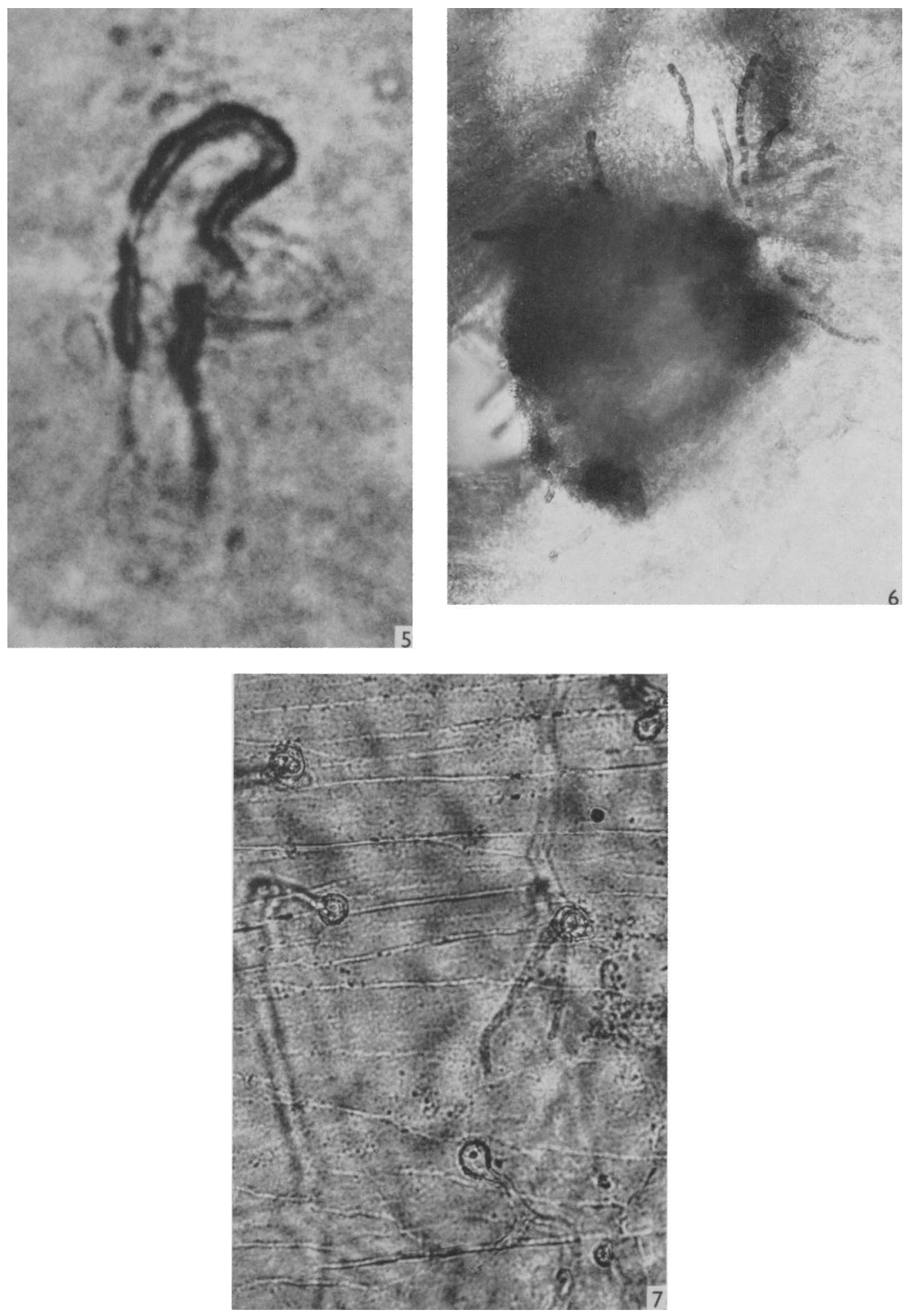

T. UNESTAM ANO D. W. WEISS 